\title{
From the Four Generations Cohabitation Family to the Dink Family: The Evolution of Chinese Young People's Family Concept
}

\author{
Wu Yiwen ${ }^{1,}$,, Yin Yiqiu ${ }^{2}$ \\ ${ }^{1}$ Department of Humanities and Social Sciences, Paris Descartes University, Paris, France \\ ${ }^{2}$ Library, Xi'an Polytechnic University, Xi'an, China \\ Email address: \\ 478484123@qq.com (Wu Yiwen) \\ ${ }^{*}$ Corresponding author
}

To cite this article:

Wu Yiwen, Yin Yiqiu. From the Four Generations Cohabitation Family to the Dink Family: The Evolution of Chinese Young People's Family Concept. Humanities and Social Sciences. Vol. 7, No. 2, 2019, pp. 71-75. doi: 10.11648/j.hss.20190702.14

Received: April 9, 2019; Accepted: May 23, 2019; Published: June 15, 2019

\begin{abstract}
China's family planning policy has achieved remarkable results in controlling the excessive growth of population, but it has also caused a series of problems, such as labor shortage, consumption depression and so on, especially the impact on the traditional family values of young people. Young people do not want to have more children, or even one child, which will have a huge impact on the development of Chinese society. This paper probes into the reasons of the evolution of family values of young people in China from the aspects of living burden and social security system etc. The paper pointed out that the evolution of family values of young people in China will have a great impact on social development. Every family has two children, which is beneficial to social development. In order to solve young people's worries about having more children, a good social security system should be established.
\end{abstract}

Keywords: Four Generations Cohabitation, Dink Family, Family Concept, Population, Social Security System

\section{Introduction}

China is the birthplace of Confucian culture. Thousands years of Confucian culture has created the Chinese traditional family concept in China [1]. The Chinese traditional family concept has played a very important role in maintaining the social stability. Chinese traditional family concept advocates multi-generation cohabitation, and "the four generations cohabitation" was once the everyone envied family model. With the development of China's reform and open policy, the intensification of social mobility and differentiation, as well as the diversification of value orientation and lifestyle, young people's family concept has changed greatly [2]. From several generations cohabitation together to the stem family, the nuclear family, the Dink family, and then to the "single family", the traditional family model has gradually collapsed. As well-known, China is the most populous country in the world, according to the National Bureau of Statistics of China until the end of 2018, Chinese population reached 1.39 billion [3]. China's huge population has caused difficulties in all aspects, for example, China's famous Spring Festival Transport is the largest annual population migration in the world [4]. In fact, population ageing is an important cause of the crisis of European democracy [5]. Face to the population pressure, China has taken steps to reduce its population. China's National Population and Family Planning Commission reports that the one-child policy has reduced 400 million people [6] For a very long time, this policy had a lot of controversy. In 2016, the Chinese government finally decided to stop this policy in the face of the aging of population by giving people the right to have "erhai" (a second child). As Olga S. Alekseeva, Irina E etc. pointed that the image of the ideal family for modern preschoolers is a family with two children [7]. So the two children policy is good both from the theoretical and practical point of view. But it is interesting that in the age of family planning in China, many couples risked being punished by trying to have one more child, today, when the government encourages the birth of two children, many couples choose not to follow this 
tendency, even not to have just one child. In 2017, China saw 8.83 million "erhai", an increase of 1.62 million compared to the previous year. It is clear that the total number of births in 2017 is 17.23 million with a birth rate of $12.43 \%$, lower than in 2016 (17.86 million births, a birth rate of $12.95 \%$ [ [8]). In other words, the reduction in the number of births is not due to the reluctance of young couples to have a second child, it is because quite a few young couples do not want to have even one child. According to the 2013 census, China has 249 million unmarried people, including about 10 million unmarried males and nearly 6 million unmarried females. Nowadays, an increasing number of young Chinese prefer not to marry. Surveys show that there are nearly 20 million young "one households" between the ages of 20 and 39. Over the past 30 years, the two indicators of Chinese Dink, Dink Behavior and Dink Willingness, have increased significantly.

About Dinking Behavior: In 1994, the proportion of Dink households in Shanghai urban areas was $4 \%$. In 2002, the proportion of Dinking households in Shanghai urban areas increased to $12.4 \%$. About Dink's Willingness: a comprehensive national survey conducted by the Department of Sociology of China Renmin University showed that $30 \%$ of the post-80s generation agreed with Dink. This article aims to analyze why Chinese young people, willing to have more children in the past, but unwilling to have more or even no children now. The evolution of Chinese young people's family concept has aroused widespread concern among sociologists. CHEN She-ying pointed out the relationship between population aging and social policies. CHEN said "Chinese family, particularly its care function, has been affected dramatically by population and birth control measures as one of the country's basic policies, from so-called "4-2-1" family structure under the "one child" policy to an emerging "4-2-2" pattern due to the recent conversion to "two child" policy. This may benefit future elder care by the family, though for the "baby boomers" as parents of the singleton generation, their care in old age will become even more problematic due to doubled childrearing burden of their adult children" [9].

It is also worried whether the evolution has positive or negative effects on China's social and economic development [10-13]. In this article, we will discuss the reasons why the Chinese young people's family concept evolved.

\section{Methodology}

The method of interview was adopted in this paper. Dozens of young Chinese couples in five major Chinese cities were surveyed. Several aspects are taken into account to see the reality in this populated giant. Our respondents include young couples with or without children, and singles over 25 years old.

\section{Results}

The traditional family concept of more and more young people has evolved and is evolving. They do not adhere to the traditional family concept of inherit. Young people who prefer to one child family even Dink family are increasing. The main reason why young people are reluctant to have more children is the huge cost of raising children and supporting the elderly. To solve the problem that young people are unwilling to have children, a sound social security system is need to establish.

\section{Discussion}

There are many factors which affect the evolution of family values of young people.

\subsection{The Formation of Self-Value Is Higher Than Family Value}

Influenced by the free spirit of Occidental world, a formation of a pluralistic life style and an improvement of educational background and vision, young people emphasize the exertion and enjoyment of their own values. They do not think that inherit is the most sacred mission, or that "marriage and child-bearing" is an indispensable part of life.

With an increasing level of mobility, young people are more open-minded, more willing to go to western world and the unknown worlds, to show and realize their own willingness. Young people are unwilling to be fettered by raising children on their own. The attitude of Chinese young people on mobility is the concrete embodiment of Jacques Perriault's theory that mobility is rising as a basic social value [14]."

\subsection{The Cost Is Not a Joke}

\subsubsection{Young Couples Without Child Worry About Having Children}

It is difficult to calculate the costs of raising a child (up to 18 years old) in China. The amount varies from one region to another. In big Chinese cities like Beijing and Shanghai, 1 million RMB (156 thousand US\$) is needed for a modest calculation.

"I got married two years ago. I'm not ready to become a dad, my wife either. My colleagues and my friends who have one or two children are no longer free. It's the end of freedom. In addition, they always talk about the daily expenses of their child, which scares us. They will also pay a lot of money for children's schooling and their future marriages ... For all I say! We must think if we are ready to have our child!'(XK, employed at a foreign company in Shanghai).

\subsubsection{Couples with Children Feel Stressed}

A couple with one child is under a huge pressure, the pressure will not only double if a couple has two children.

"I have a two-year-old daughter, I want to have two children before getting married, but now I realized how ignorant I was. Who gave me the courage?" (ZY, a teacher in Xi'an, capital of Shaanxi Province).

"The cost of raising a child is elusive, and I never thought about it. All his actions require money! Eat, drink, playing ... We only buy powdered milk from New Zealand, 289 RMB for just a bottle of milk (40 US\$). We buy other things from Europe and it's so expensive. I earn 8000 RMB (1189 US\$) every month, not bad in Xi'an. For now my wife does not work. 
My daughter makes us spend the majority, on average 5000 RMB monthly. She also has some hobbies. For example she is learning to paint. We plan to buy a piano when she is 3 years old. Everyone does it, so we can't be late."

Chinese babies start spending money when they are born. Now domestic products are no longer preferred for security reasons even if their prices are lower. Parents ask their children to take part in various courses to develop their hobbies so that they will not lose at the starting line. One child requires a huge expense, and the second child means everything will be doubled.

\subsubsection{Raising a Child Is a Lifetime Expense}

When children reach school age, another expense comes.

"I have two children, an 8-year-old girl and a 3-year-old boy. My daughter is in Grade Two at elementary school. We chose a good school but a bit farer because the school in our neighborhood is not satisfactory enough. We have to pay 30 thousand RMB (4.46 thousand US\$) to keep this place, and we also pay annual registration fees, 60 thousand RMB (9.92 thousand US\$) each year. For my boy we will choose a bilingual kindergarten so that he can learn English. We hesitate between two schools, the first is better but we have to pay 80 thousand RMB every year! More expensive than my daughter's school. The price goes up every year."(YF, employee at a Japanese company in Shanghai).

Theoretically, going to a nearby school is the cheapest way for child's parents. Unfortunately the qualities of the schools are very diverse. Parents prefer schools with a good reputation, but these kinds of schools are not enough and very choose to students. Children are required to pass an exam to see their level of intelligence and only those who have passed the exam have the chance to pay an extra commission to enter these schools. The reason of commission is that they are not in this neighborhood and they have to pay for a position. Parents, in this case, agree to pay these fees so that their children may have an opportunity to enter for the so-called key schools.

"They are still young, my children. If one day they want to study abroad... We have a long way to go, "says YF."We also have to buy an apartment for our son when he gets married. In Shanghai, it's something!"

Tuition fees can't be neglected by Chinese parents. Studying abroad is a big trend in China, especially for parents who have expectations of their child. Europe, the United States and Australia are privileged despite the high costs. After leaving school, children will enter a new stage of life, for example, getting married, usually the boy's parents are supposed to buy an apartment for the young couple, which is a novel rule. In addition, more and more parents are also preparing the same thing for their daughter so that she can have an equal position to her husband, especially for the single daughter of the family. Generally, In Beijing, the price is 15486.6 USA\$ per square meter in town. In Shanghai it is less difficult, 8951.2 USA\$ per square meter. If you want to buy two apartments, it's easy to imagine the pressure of parents.

\subsection{To Bear the Double Pressure of Supporting Parents and Children}

Young couples have to take care not only of their child, but also of their parents. Due to the one child policy, a young couple cares for 4 elderly people. This is the famous model "4-2-1", and it becomes "4-2-2" if this couple has two children. The social security system in China is complicated and consists of several disparate regimes. Old-age insurance comprises four schemes: civil servants, urban workers, urban and rural unemployed. Health insurance treats urban workers, urban residents and rural residents differently. The welfare provided by social security system varies greatly across groups and regions in China. Public service employees are particularly favorable because they can receive high pension after their retiring, that means $90 \%$ of their salary will be remained, while the company employees could get only $59.2 \%$ of their salary for the pension ${ }^{[15]}$. After the government has done a lot of work, although the life of farmers is much better than before, the social security system of farmers is worse than that of civil servants and urban residents.. The old Chinese proverb says "yang er fang lao", which means "old age security is to have sons". When the social security system is not able to cover the entire population, the elderly are still dependent on their children. Chinese people like to say "shang you lao, xia you xiao", which means that a person has parents to look after, and children to raise, to describe the young people's difficult situation. JP (freelancer in Chengdu, Sichuan) tells us his worries on this topic:"You cannot choose your parents, but you can choose your future. If I have more money, I will prefer to give my parents a better life. I'm single, it does not bother me. When I'm 70, I will spend last time of my life in a good nursing home".

There are many young people who share JP's ideas, Therefore, a good social security system is the guarantee that young people dare to bear children.

\subsection{The Social Security System Is Not Guaranteed}

In July 2018, China had a big scandal about vaccines. Changchun Changsheng, the second largest public laboratory, falsified data and modified production parameters. The illegal rabies vaccine produced in this laboratory has aroused the panic of young Chinese parents. Many Chinese think that to have a child is to put him in danger.

"It's too shocking! I had my eldest daughter vaccinated in Hong Kong with foreign vaccines, but my second daughter was vaccinated in Guangzhou, I regretted it very much. The vaccine is to protect the vulnerable, not to kill them! I am very angry! It's outrageous" $(\mathrm{XY}$, senior accountant at a private company in Guangzhou).

Food and health scandals are constantly appearing. In 2008, the melamine milk incident shocked the whole country. The SanLu Milk Company put melamine into milk powder to make them appear richer in protein. On December $1^{\text {st }} 2008$, the Ministry of Health updated its published figures, confirming 
that almost 300,000 children became ill after consuming this contaminated milk powder. Small victims are called "baby with big head" because of the symptom caused by the melamine milk.

Thanks to the Internet, scandals no longer have the possibility of being hidden, especially those concerning children. Anyway, the Chinese young couples are more worried for their children.

\subsection{There Are More Choices for Women}

Chinese girls are increasingly well educated. Late marriage is seen among girls with a high level of education. There are also some girls who prefer to stay single, or have a child much later than before.

CX, 26, PhD student at Peking University, tells us about her experiences.

"I am single for the moment. It does not bother me, but my parents are worried. They organized a lot of blind dates for me but it seems not useful. The young men I met, are, how to say, less competent than me, but macho. They think that women have to stay at home to take care of the family. Sorry, I do not agree."

For young graduates, to have a work is the prerequisite for independence and individual autonomy, in the new era, women are no longer willing to subordinate to men. When we ask our interviewees how to choose if there were a conflict between family life like having a child and working life. 8 people say that they will develop their job first. 3 young women think that they can find a balance between these two, which means, work less hard and have a child at the same time. There are still 2 women who say that they would give up their work if they have to choose between work and family life. So we can see that professional identity counts for a lot of young Chinese.

On another aspect it may explain why young Chinese women take their work seriously. In the labor market, women are more disadvantaged than men who do not need to take maternity leave. The situation is worse now because women have the opportunity to have a second child. Men can keep a steady pace while women are very disturbed by the arrival of child and that means they have to sacrifice their professional life.

$\mathrm{XM}$, an employee of Shanghai University, mother of two girls, keeps complaining about her husband.

"I feel like a single mother with these two demons. My husband is irresponsible. He goes to the party with his colleagues on the pretext of cultivating an interpersonal social network. I understand it but it's impossible for me to take care of these two children at the same time. I often tell him to come home early, because you're a father of two children!!! He is better now but I still feel helpless. I have not been working for 3 years because I had to stay at home for them. Now they are in kindergarten, I can breathe. I always tell my husband that we are equal, so we must invest in the same way and I am not your housekeeper"

The sharing of the parental role between the couples requires a reflection on the notion of parental responsibility. Not all parents are ready
$\mathrm{XM}$ confirms that it is hard to work now. She does not get used to the pace of working, the worst part is that she always thinks about her children when she works.

"But I have to adapt to it, because I need this job. I do not want to be a housewife, otherwise I will feel lost. My work gives me an independent identity."

\section{Conclusions}

A better solution is needed.

To have a child or not is a private decision. But in 2018, researchers emit the idea of charging a tax on those who have no child under the age of 40, regardless of their gender. The tax will not be stopped until they have two children. This policy is supposed to stimulate the birth rate in the face of the aging of the population. This tax would be deducted directly from the salary and would be used to fund a maternity support fund. This proposal has worried many young Chinese people because they will have a grand burden.

China has undergone a great transformation before and after the implementation of the one-child policy. Nowadays the policy of second child seems to meet another obstacles. Such a policy may not be efficacious if people feel forced. With the aging of the population, a better solution is to reform the social security system instead of pushing on people.

Traditional family values are crumbling in young people.

From several generations of cohabitation to the main family, the nuclear family, the Dink family, and then to the "one family", the traditional family model has gradually collapsed among the young people in China. Young people underline individualism and freedom, and that is why their Self-worth is embodied. As for the development of society, measures should be taken to deal with demographic crisis and the challenge of the social security system.

\section{References}

[1] LIU Yun-xiang. Family Value and Social Security System under the Background of Confucian Cultural Circle [J], Journal of Chongqing University of Posts and Telecommunications (Social Science) 2009, Vol. 21 (06): 55-58.

[2] TANG Ya-hui. The Trend of Family Concept in Contemporary China [J]. Social Sciences in Hunan, 2000 (03): 31-32.

[3] http://news.cnr.cn/native/gd/20190121/t20190121_524489092 .shtml.

[4] Zhao Z Y, Wei Y, Pang R Q, et al. 2017. Spatiotemporal and structural characteristics of interprovincial population flow during the 2015 Spring Festival travel rush [J]. Progress in Geography, 2017, 36 (8): 952-964.

[5] CHENG Tong-shun, SHI Meng. Democratic Dilemma in European Aging Society [J], Contemporary World and Socialism, 2019, (02).

[6] "Decision on Enhancing Population and Family Planning Work in an All-round Way to Solve Population Problems", The Central Committee of the Communist Party and the State Council of China, 2010. 
[7] Olga S. Alekseeva, Irina E. Rzhanova, Anna Ya. Fominykh, Nadezda M. Zyryanova. Family and Sibling Relations Concepts of Preschoolers [J]. Procedia - Social and Behavioral Sciences, 2016, 233.

[8] http://www.stats.gov.cn/tjsj/zxfb/201801/t20180118_1574917. $\mathrm{html}$.

[9] CHEN She-ying. Population Ageing and Social Policies [J], Population and Society, 2017, 33 (1): 63-72.

[10] XU An-qi. On the Change Characteristics of Family Values [J]. Academic Journal of Zhongzhou, 2013 (04): 75-81.

[11] SUN Tao, JING Shuguang. Family Value, Demographic Dependency Ratios and National Savings: Empirical Study
Based on World Value Survey [J], World Economy Studies, 2016 (5): 99-111.

[12] PAN Xiao-ming. Research on the Construction of Family Values in Modern China [J], Social Sciences in Guangxi, 2018 (03): 189-193.

[13] YANG Ge. The Impact of Social Transformation on Family Structure and Intergenerational Residence Model [J]: Data from Shanghai, Zhejiang and Fujian Province, Population Journal, 2017, 39 (02): 5-17.

[14] Jacques Perriault, personal digital traces, uncertainty and social relationship, Hermès, 2009/1, p. 13-20

[15] https://cn.ambafrance.org/La-protection-sociale-en-Chine. 